\title{
Complications of spinal surgery in acute spinal cord injury
}

\author{
J E Carvell MMSc FRCS, ${ }^{1}$ D J Grundy FRCS ${ }^{2}$ \\ ${ }^{1}$ Consultant Orthopaedic Surgeon, Salisbury District Hospital, ${ }^{2}$ Consultant in Spinal \\ Injuries, Duke of Cornwall Spinal Treatment Centre, Salisbury District Hospital, \\ Salisbury SP2 8BJ, England.
}

\begin{abstract}
Despite an increasing realisation that patients with acute spinal cord injuries require a multidisciplinary approach for their management, which can only be satisfactorily provided in spinal injuries units, these units are still not being used to their full potential in the United Kingdom. Not surprisingly, the initial admission of patients to other hospitals has inevitably led to delays in transfer to such units, with a high incidence of complications. The results of spinal surgery were studied in 420 consecutive patients with spinal cord injury admitted to the Duke of Cornwall Spinal Treatment Centre, Salisbury. Complications were more frequent in patients undergoing spinal surgery before transfer to the centre. Furthermore, the longer the delay in transfer, the higher the incidence of pressure sores. Suggestions are made as to how complications can be avoided in future.
\end{abstract}

Keywords: spinal cord injury; delayed transfer; complications of spinal surgery; spinal injuries units.

\section{Introduction}

Over the last 30 years it has become increasingly accepted that patients with an acute spinal cord injury require a multidisciplinary approach for their management, which can only be satisfactorily provided by a spinal injuries unit. ${ }^{1}$ The fact is, however, that in the United Kingdom at least, the great majority of patients are initially admitted to other hospitals. A minority are unfit for early transfer, because of multiple injuries or respiratory insufficiency, but all other patients should be admitted to the nearest spinal unit without delay. Unfortunately, this does not always happen. ${ }^{2}$

The opening of the Duke of Cornwall Spinal Treatment Centre in Salisbury in 1984 provided the opportunity to examine the pattern of initial treatment and transfer of such patients in the south and south west of England, particularly in relation to the timing of and results of spinal surgery. The complications of spinal surgery in patients having their operation before transfer to the spinal centre were compared to those having their surgery in the spinal centre.

\section{Patients and methods}

Four hundred and twenty consecutive patients admitted to the centre from 1984 to 1991 with an acute spinal cord injury were studied. One hundred and fifty eight (37\%) underwent surgery to stabilise the spine. In 127 patients $(30 \%)$ spinal surgery was performed before transfer to the spinal centre, and only 31 patients (7\%) underwent surgery in the centre. Of the 160 cervical patients admitted to the spinal centre without having had spinal surgery, 13 required an operation. The indications for surgery were an unreduced dislocation or spinal instability. Similarly, 18 of the 133 patients with injuries to the thoracic, thoracolumbar or lumbar spine, who were admitted to the spinal centre without having had spinal surgery required an operation, the main indications for surgery being an unreduced dislocation or spinal instability, often associated with severe pain. This surgery was performed in the spinal centre by the same (orthopaedic) surgeon, who was fully accustomed to, and regularly performed spinal surgery, both for trauma and other spinal conditions. One each of the thoracolumbar 
and lumbar fractures were treated by a combined approach of a neurosurgeon and the same orthopaedic surgeon. No protocols for the initial management and transfer to the spinal centre had been agreed with referring hospitals, and consequently several patients experienced considerable delay in their admission to the centre.

Of the 158 patients who had undergone spinal surgery for their injury (Table I), only $34(21.5 \%)$ were admitted to the spinal centre within 48 hours of injury. In the 127 patients whose spinal operation was performed before admission to the centre, the most common reason for delay in transfer $(35 \%)$ was spinal surgery and its complications (Table II). Eighteen patients had undergone multiple transfers, having been first moved to a hospital where spinal surgery was available, before transfer to the spinal treatment centre.

\section{Results}

Of the 127 patients undergoing spinal surgery before transfer to the spinal centre, 23

Table I Site of injury and operation rate

\begin{tabular}{lcc}
\hline Site of injury & $\begin{array}{c}\text { Number of } \\
\text { patients }\end{array}$ & $\begin{array}{c}\text { Number under- } \\
\text { going surgery }\end{array}$ \\
\hline Cervical & $208(50 \%)$ & $61(29 \%)$ \\
Thoracic & $121(29 \%)$ & $31(26 \%)$ \\
Thoracolumbar & $69(16 \%)$ & $51(74 \%)$ \\
Lumbar & $22(5 \%)$ & $15(68 \%)$ \\
Total & 420 & $158(38 \%)$ \\
\hline
\end{tabular}

$(18 \%)$ required further surgery for various complications (Tables III, IV), 13 of these operations being performed in the spinal centre.

Not all surgeons adopted a uniform policy of bone grafting following internal fixation. All patients undergoing surgery in the spinal centre had a bone graft, with a complication rate of $16 \%$, and a reoperation rate of $6.5 \%$ (Tables V, VI). Only 83 of the 127 patients (65\%) undergoing surgery before admission to the spinal centre were bone grafted and $23(28 \%)$ developed complications. Seventeen of the 44 patients who were not bone grafted $(39 \%)$ developed complications. Orthopaedic surgeons used bone grafts in $81 \%$ of their cases, compared to a bone graft rate of only $50 \%$ by neurosurgeons. The overall complication rate in the group of 127 patients was $31 \%$ ( 40 patients).

The 127 patients were treated either by orthopaedic surgeons $(68 \%)$, neurosurgeons $(22 \%)$, or by a combined approach $(3 \%)$, and in $7 \%$ the discipline was not known. There did not appear to be a particular bias in the complications seen in relation to the site of injury or the discipline of the surgeon.

One of the more serious complications caused by the delay in admission to the spinal centre was the development of pressure sores. No sores were seen in patients admitted to the centre within 48 hours of injury, but if transfer was delayed by 8 days or more, the incidence of pressure sores was $14 \%$ in patients who had been treated conservatively, and $29 \%$ in those who had had spinal surgery.

Table II Reasons for delay in admission ( 8 days or more) to a spinal centre in 158 patients undergoing spinal surgery

\begin{tabular}{lc}
\hline Main reason for delay in admission & Number \\
\hline Surgery and its complications & $55(35 \%)$ \\
Multiple injuries & $17(10.5 \%)$ \\
Other complications & $9(5.5 \%)$ \\
Distance & $17(11 \%)$ \\
Multiple transfers & $18(11.5 \%)$ \\
Difficulty in admission to a spinal centre & $3(2 \%)$ \\
No specific reason & $5(3 \%)$ \\
No delay (admitted within 48 hours of injury) & $34(21.5 \%)$ \\
Total & $158(100 \%)$
\end{tabular}


Table III Cervical injuries. Complications of surgery in 48 patients undergoing operation before transfer to spinal centre

\begin{tabular}{lcc}
\hline Complication & $\begin{array}{c}\text { Number } \\
\text { of } \\
\text { patients }\end{array}$ & $\begin{array}{c}\text { Number of } \\
\text { patients } \\
\text { requiring } \\
\text { further surgery }\end{array}$ \\
\hline Failure to recognise or reduce dislocation & 4 & 1 \\
$\begin{array}{l}\text { Graft shift } \\
\text { Myelographic block after posterior surgery, due to anterior }\end{array} \quad 1$ & 1 \\
$\quad$ osteophytic bar & 1 & 1 \\
Recurrent laryngeal nerve palsy after anterior instrumentation & 1 & - \\
Screws of anterior plate displaced, causing dysphagia & 1 & 1 \\
Inappropriate sublaminar wires & 1 & - \\
Flexion deformity due to inadequate fixation & 2 & - \\
Wound infection & 1 & 1 \\
Total & $13(27 \%)$ & $6(12.5 \%)$ \\
\hline
\end{tabular}

Table IV Thoracic, thoracolumbar and lumbar injuries. Complications of surgery in 79 patients undergoing operation before transfer to spinal centre

\begin{tabular}{lcc}
\hline Complication & $\begin{array}{c}\text { Number } \\
\text { of } \\
\text { patients }\end{array}$ & $\begin{array}{c}\text { Number requiring } \\
\text { further operation }\end{array}$ \\
\hline $\begin{array}{l}\text { Pain due to incorrect technique, with displacement or } \\
\quad \text { racture of implant, or failed bone graft; nerve root }\end{array}$ & 16 & 12 \\
$\quad$ entrapment & 6 & - \\
Complications of instrumentation without symptoms & 2 & 3 \\
Neurological deterioration & 3 & $17 / 79(22 \%)$ \\
Wound infection & $27 / 79(34 \%)$ & \\
\hline
\end{tabular}

Table V Complications of surgery in 31 patients undergoing operation in a spinal centre

\begin{tabular}{llc}
\hline Complication & $\begin{array}{c}\text { Number } \\
\text { of } \\
\text { patients }\end{array}$ & $\begin{array}{c}\text { Number of } \\
\text { patients } \\
\text { requiring } \\
\text { further surgery }\end{array}$ \\
\hline Graft shift & 2 & - \\
Re-displacement of reduced dislocation & 1 & - \\
Harrington rod hook displacement & 1 & 1 \\
Harrington rods painful-trimming required & 1 & 1 \\
Total & $5(16 \%)$ & $2(6.5 \%)$ \\
\hline
\end{tabular}

\section{Discussion}

Whilst all spinal injuries centres in this country are prepared to accept patients immediately after injury, this still does not seem to encourage accident, orthopaedic and neurosurgical departments to liaise in the initial phase of treatment of the spinal cord injured patient. The early transfer of virtually all patients is desirable and some 
Table VI Complications of surgery and reoperation rate

\begin{tabular}{lccc}
\hline & $\begin{array}{c}\text { Number } \\
\text { of } \\
\text { patients }\end{array}$ & $\begin{array}{c}\text { Number of } \\
\text { patients with } \\
\text { complications }\end{array}$ & $\begin{array}{c}\text { Patients } \\
\text { requiring } \\
\text { reoperation }\end{array}$ \\
\hline $\begin{array}{l}\text { Patients undergoing initial surgery before } \\
\text { transfer to a spinal centre (127 patients) }\end{array}$ & 48 & $13(27 \%)$ & $6(12.5 \%)$ \\
$\begin{array}{l}\text { Cervical } \\
\text { Thoracic }\end{array}$ & 26 & $6(23 \%)$ & $3(11.5 \%)$ \\
$\quad$ Thoracolumbar & 43 & $16(37 \%)$ & $9(21 \%)$ \\
$\quad$ Lumbar & 10 & $5(50 \%)$ & $5(50 \%)$ \\
$\quad$ Total & 127 & $40(31 \%)$ & $23(18 \%)$ \\
Patients undergoing initial surgery in a spinal & & & \\
$\quad$ centre (31 patients) & 13 & $1(8 \%)$ & - \\
$\quad$ Cervical & 5 & $1(20 \%)$ & $1(20 \%)$ \\
$\quad$ Thoracic & 9 & $2(22 \%)$ & $1(9 \%)$ \\
$\quad$ Thoracolumbar & 4 & $1(25 \%)$ & - \\
$\quad$ Tumbar & 31 & $5(16 \%)$ & $2(6.5 \%)$ \\
$\quad$ Total & - & - & \\
\hline
\end{tabular}

centres, for example the spinal unit in Perth, Western Australia, succeed in admitting $91 \%$ of patients within 24 hours, and $95 \%$ within 48 hours of injury. ${ }^{3}$ Bed availability has not been a problem in Salisbury, delay in transfer to our centre of patients who had had their spinal surgery elsewhere occurring in only three instances $(2 \%)$.

The long term benefits of early admission have been stressed by spinal injuries units in this country and in all countries who have developed such units. ${ }^{1}$ It is well recognised that complications such as pressure sores, urinary tract and respiratory complications are higher in those in whom admission is delayed. It is therefore not surprising, but nevertheless disappointing, to see such a high incidence of pressure sores in patients whose admission to the spinal centre was delayed, especially when spinal fixation should facilitate nursing and consequently decrease the incidence of sores. Pressure sores are preventable problems and are all the more so when the reasons for delay are analysed.

Multiple injuries with life-threatening conditions meant that, understandably, $11 \%$ of patients' transfers to the spinal centre were delayed. The reason for delay in transfer in $35 \%$ was surgical intervention and related complications. Whilst the report of the working party on spinal injuries units in $1984^{4}$ felt that it was inevitable that patients with multiple injuries would be taken first to the nearest major trauma centre and that some tetraplegic patients would require to be ventilated as an emergency life-saving measure, this does not excuse the admitting unit from discussing the nature of the injury with the medical staff in the nearest spinal injuries unit. Early contact and advice, or possibly a visit from a consultant from the spinal injuries unit, may prevent inappropriate treatment being instituted and complications occurring. It is a sad flection that in this day of the helicopter and increasing deployment of paramedical staff, more patients are not airlifted to a specialised centre, either for resuscitation and or for definitive treatment. ${ }^{5}$ The multiple transfer of patients in search of a surgeon to stabilise the spine before admission to a spinal unit should certainly be a thing of the past. In Switzerland, the introduction of a nationwide helicopter rescue system for patients with spinal cord injuries has reduced the overall mortality by $80 \% .^{6}$

Of equal concern is the complication rate of spinal instrumentation and the high reoperation rate. Some complications have resulted from technical failure and others from inappropriate or inadequate spinal instrumentation (Fig 1). Sadly, some seem 
a

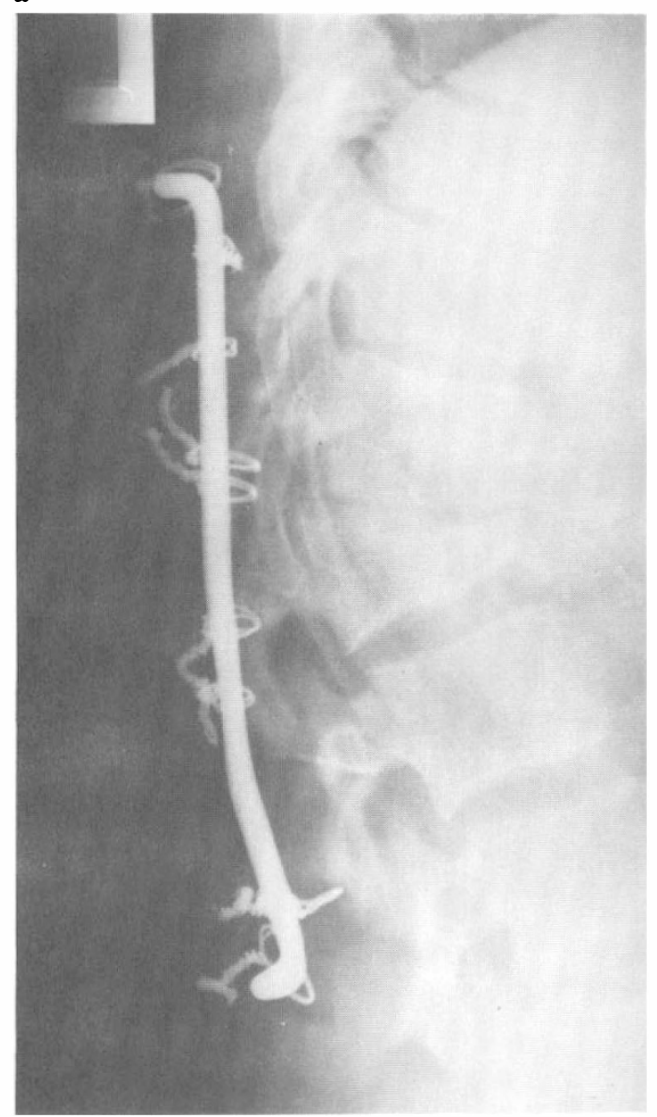

b

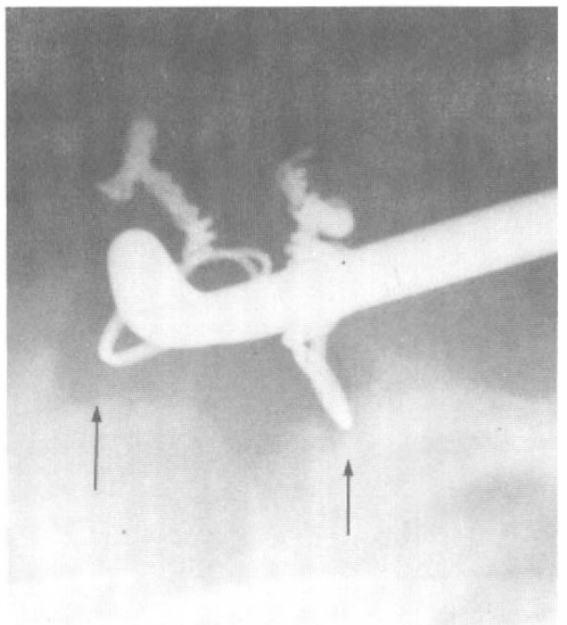

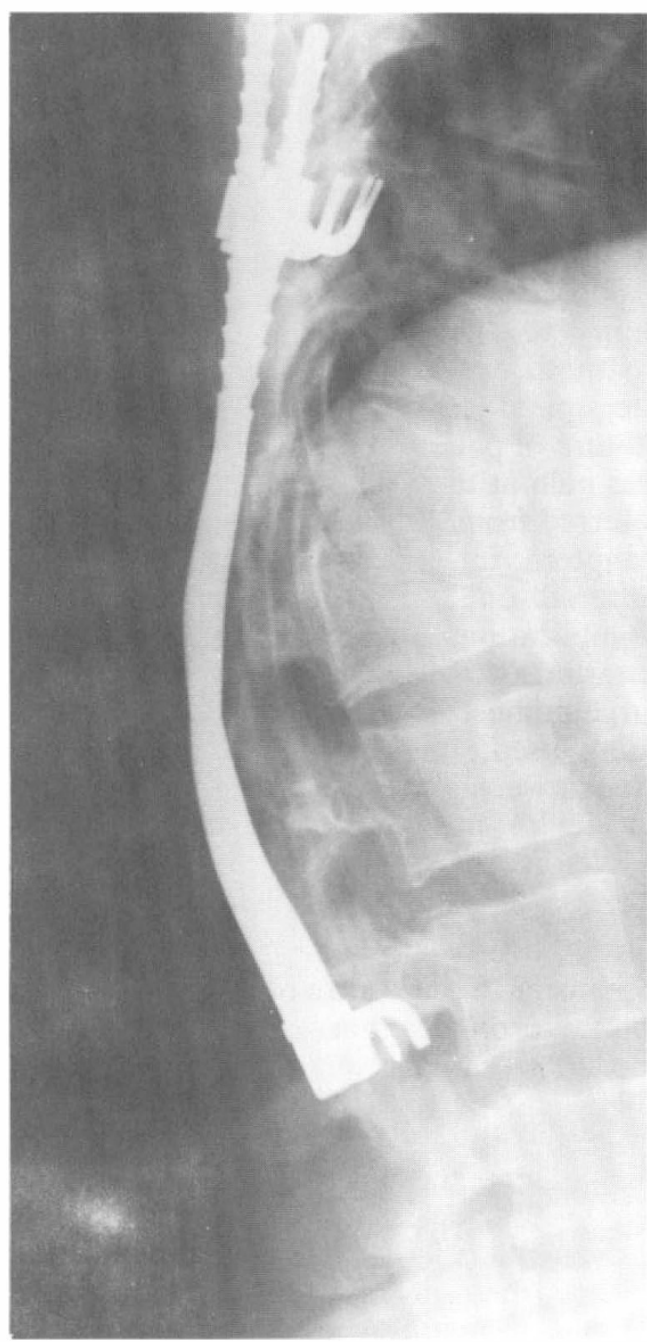

Figure 1 (a) Inappropriate transosseous placement of sublaminar wires. (b) Leading to bony erosion (arrowed) and severe pain. (c) Necessitating removal of the Hartshill rectangle and wires, and secondary stabilisation with Harrington rods and posterior bone graft. 
to be due to the lack of skills in the use of spinal instrumentation. It would appear that some doctors fail to understand the pathophysiology of the injury that they are dealing with, resulting in poor surgical stabilisation with inappropriate instrumentation. We feel that adequate bone grafting is essential to help to establish a solid bony support for the spine at the level of the injury to ensure that intrinsic stability is restored, eventually relieving the stress on the spinal implant. The most disabling feature of patients requiring further surgery was pain at the fracture site or occasionally referred from the spine. This is a distressing symptom for patients who have already suffered one significant traumatic insult. Complications can usually be avoided with care and attention to detail. We feel that the surgeon must be conversant with the device being used, and with its limitations. Although we would not advocate one particular device in preference to another, our results in the thoracic and lumbar spine

a

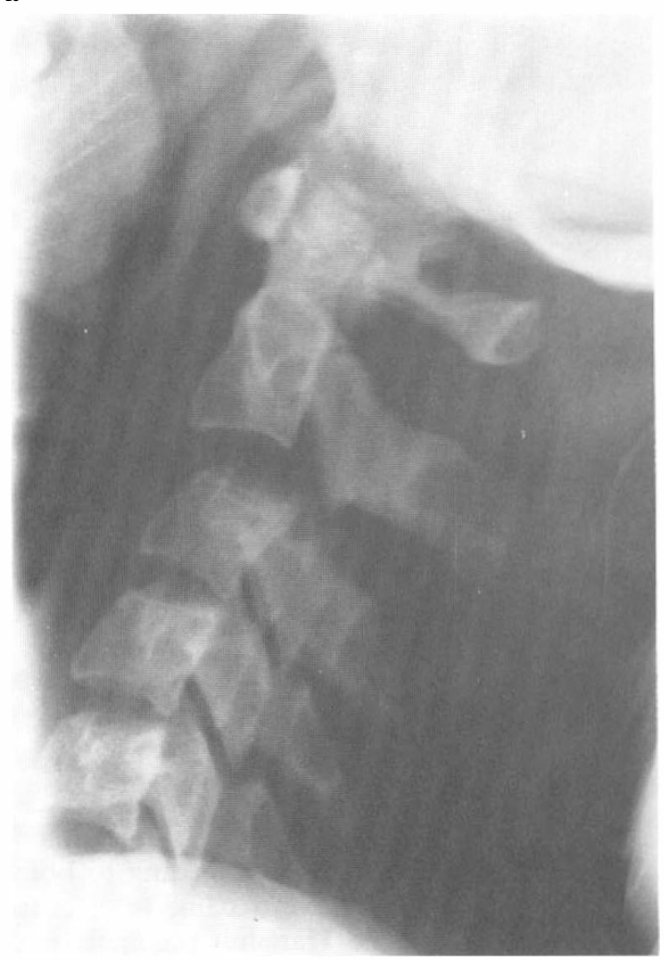

were obtained using contoured squareended Harrington rods with bifid upper hooks, combined with adequate posterolateral and facet grafting over the instrumental segment. The shortest possible segment was fused, compatible with stabilisation of the fracture. Postoperative pain associated with immobilisation of a segment of spine was not seen using this technique. In the cervical spine, a posterior approach with interspinous and/or facet wiring with bone grafting was found to be the most universally required procedure (Fig 2). All patients were fitted with a firm supportive collar or brace until the fusion was sound.

Only one patient asked for the internal stabilisation device to be removed because of an extremely active lifestyle. One patient deteriorated neurologically after surgery but neurological benefit was not analysed in this series as the numbers were too small and no attempt was made to randomise treatment.

We believe that if surgeons are to avoid the potential pitfalls in operating on patients

b

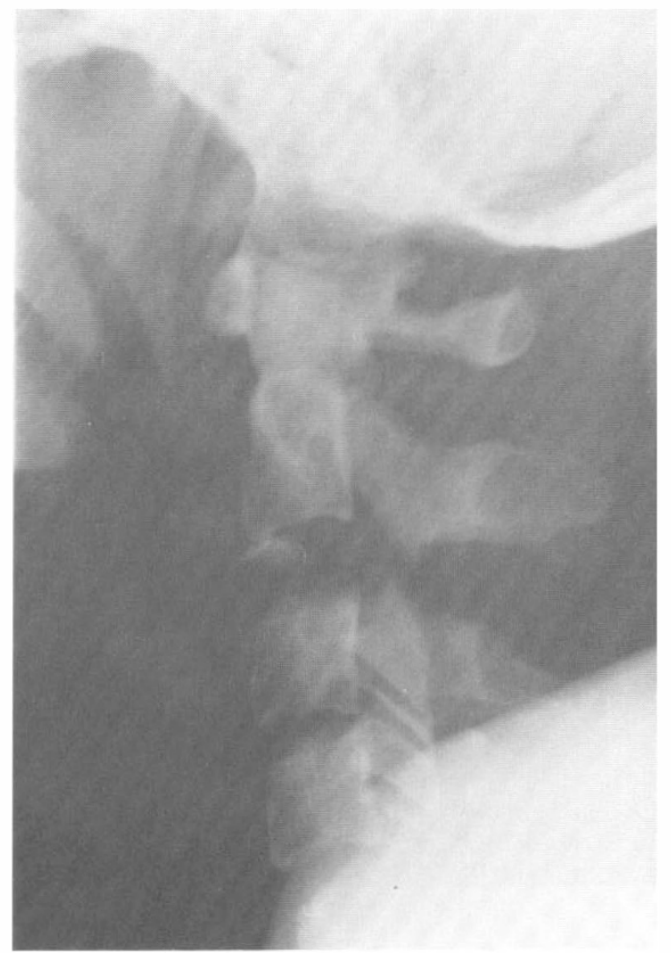

Figure 2 (a) and (b). Caption on p. 395. 


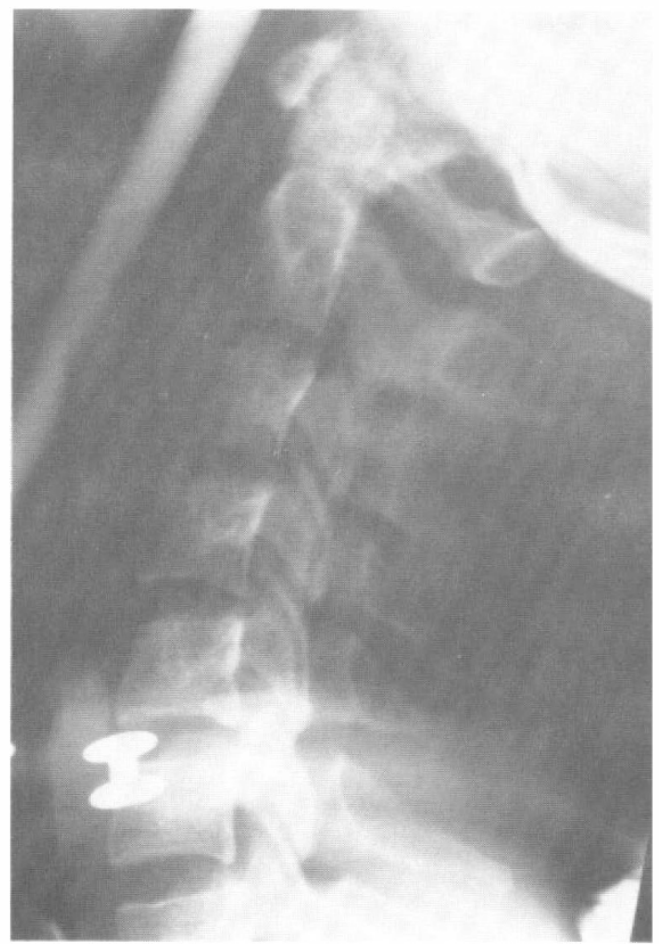

d

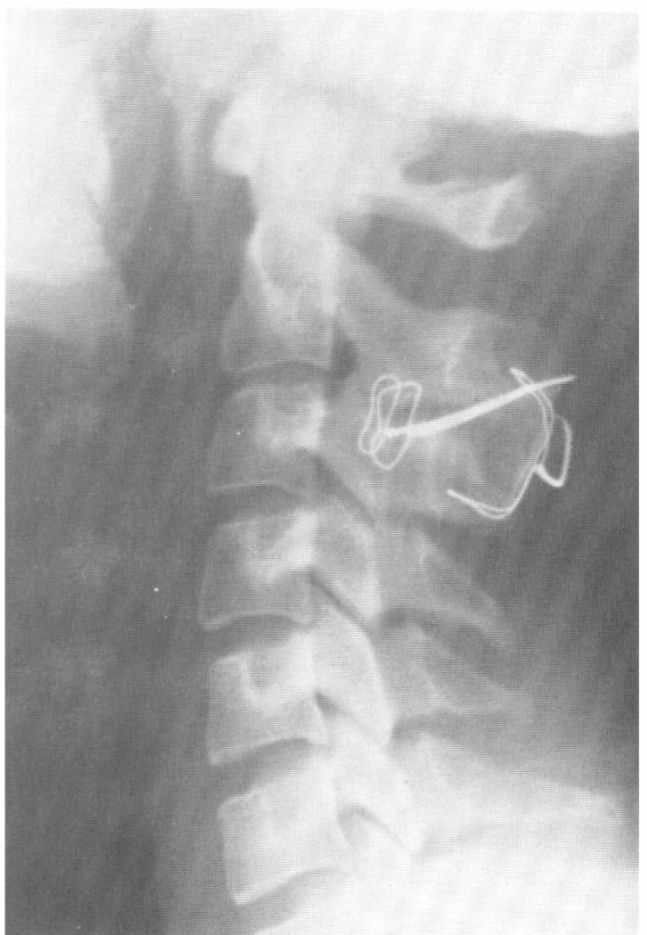

Figure 2 (a) Patient on skull traction, showing partial unlocking of facets of $\mathrm{C} 2$ and 3, and fracture of base of lamina of C2. (b) Facets unlocked on traction, but with distraction. (c) Following application of a halo brace the dislocation has been reduced. (d) Surgical stabilisation with posterior facet and interspinous wiring, and grafting.

with acute spinal cord injuries, the initial appraisal should be made by a team of doctors who are fully conversant with the modern techniques of stabilisation and instrumentation. Doctors at the district hospital where the patient is treated initially should, we believe, consult with the medical staff of the nearest supraregional spinal injuries unit so that joint decisions can be made about the initial management and the timing of transfer of patients to the specialist spinal centre.

\section{References}

1 Donovan WH, Carter RE, Bedbrook GM, Young JS, Griffiths ER (1984) Incidence of medical complications in spinal cord injury: patients in specialised, compared with non-specialised centres. Paraplegia 22: 282-290.

2 Carvell J, Grundy D (1989) Patients with spinal injuries. Early transfer to a specialist centre is vital. $B M J$ 299: $1353-1354$

3 Griffiths ER (1988) Thoraco-lumbar spinal injuries: role of the spinal injuries centre. Curr Orthop 2: 227-230.

4 Working Party for the Commission on the Provision of Surgical Services (1984) Spinal Injuries Units. Royal College of Surgeons of England, London.

5 Earlam R, Wilson A (1989) Helicopter emergency medical services. Ann R Coll Surg Engl 71 (suppl): 60-64.

6 Hachen HJ (1977) Idealised care of the acutely injured spinal cord in Switzerland. J Trauma 17: 931-936. 